\title{
Progressive Postnatal Motoneuron Loss in Mice Lacking GDF-15
}

\author{
Jens Strelau, ${ }^{1}$ Adam Strzelczyk, ${ }^{1}$ Patricia Rusu, ${ }^{1}$ Gerald Bendner, ${ }^{1}$ Stefan Wiese, ${ }^{5}$ Francesca Diella, ${ }^{2}$ Amy L. Altick, ${ }^{3}$ \\ Christopher S. von Bartheld, ${ }^{3}$ Rüdiger Klein, ${ }^{4}$ Michael Sendtner, ${ }^{5}$ and Klaus Unsicker ${ }^{1,6}$ \\ ${ }^{1}$ Neuroanatomy and Interdisciplinary Center for Neurosciences, University of Heidelberg, D-69120 Heidelberg, Germany, ${ }^{2}$ European Molecular Biology \\ Laboratory Heidelberg, D-69117 Heidelberg, Germany, ${ }^{3}$ Department of Physiology and Cell Biology, University of Nevada School of Medicine, Reno, \\ Nevada 89557, ${ }^{4}$ Department of Molecular Neurobiology, Max Planck Institute of Neurobiology, D-82152 Martinsried, Germany, ${ }^{5}$ Clinical Neurobiology, \\ University of Würzburg, D-97078 Würzburg, Germany, and 'Institute of Anatomy and Cell Biology, Department of Molecular Embryology, University of \\ Freiburg, D-79104 Freiburg, Germany
}

Growth/differentiation factor-15 (GDF-15) is a widely expressed distant member of the TGF- $\beta$ superfamily with prominent neurotrophic effects on midbrain dopaminergic neurons. We show here that GDF-15-deficient mice exhibit progressive postnatal losses of spinal, facial, and trigeminal motoneurons. This deficit reaches a $\sim 20 \%$ maximum at 6 months and is accompanied by losses of motor axons and significant impairment of rotarod skills. Similarly, sensory neurons in dorsal root ganglia (L4, L5) are reduced by $20 \%$, whereas sympathetic neurons are not affected. GDF-15 is expressed and secreted by Schwann cells, retrogradely transported along adult sciatic nerve axons, and promotes survival of axotomized facial neurons as well as cultured motor, sensory, and sympathetic neurons. Despite striking similarities in the GDF-15 and CNTF knock-out phenotypes, expression levels of CNTF and other neurotrophic factors in the sciatic nerve were unaltered suggesting that GDF-15 is a genuine novel trophic factor for motor and sensory neurons.

\section{Introduction}

Growth/differentiation factor-15 (GDF-15) is a distant member of the TGF- $\beta$ superfamily that was discovered by our and several other laboratories in the search for novel TGF- $\beta$ s (Böttner et al., $1999 a, b)$ and gene products involved in macrophage activation (Bootcov et al., 1997; Fairlie et al., 1999), placental, and antiinflammatory functions (Hromas et al., 1997; Baek et al., 2001). The rat, mouse, and human GDF-15 genes that we isolated (Böttner et al., 1999b) are composed of two exons and a single intron that interrupts the coding sequences at identical positions within the prepro-domain of the corresponding proteins. The predicted proteins contain the structural hallmarks of members of the TGF- $\beta$ superfamily, including the seven conserved C-terminal cysteine residues that form the cysteine knot. GDF-15 is synthesized as a large precursor molecule, which carries a conserved cleavage site to yield the biologically active mature protein. The orthologous molecules show the lowest sequence conservation of all members of the TGF- $\beta$ superfamily. Most investigators studying GDF-15 so far have focused on its

Received Feb. 24, 2009; revised July 1, 2009; accepted July 29, 2009.

This work was supported by grants from the German Research Foundation (Str616/1-4, Un34/23-1) and National Institutes of Health Grant EY 12841 (C.S.v.B.).We thank Marion Schmitt for skillful technical assistance. Blastocyst injection of targeted ES cells was performed by the Transgenic Facility at the European Molecular Biology Laboratory, Heidelberg. We thank Biopharm GmbH, Heidelberg, Germany, for generously supplying us with recombinant human GDF-15.

Correspondence should be addressed to Klaus Unsicker, Institute of Anatomy and Cell Biology, Department of Molecular Embryology, University of Freiburg, Albertstrasse 17, D-79104 Freiburg, Germany. E-mail: ku39@anat.uni-freiburg.

D0I:10.1523/JNEUROSCI.1133-09.2009

Copyright $(\odot 2009$ Society for Neuroscience $\quad 0270-6474 / 09 / 2913640-09 \$ 15.00 / 0$ putative functions in various pathologies and cancer including its proapoptotic roles (Liu et al., 2003; Yang et al., 2003).

GDF-15 is widely expressed in liver, lung, kidney, and exocrine glands (Böttner et al., 1999a). At lower levels, GDF-15 mRNA and protein are ubiquitously found in the CNS, its site of highest expression being the choroid plexus, which secretes the protein into the CSF (Strelau et al., 2000). GDF-15 mRNA is prominently upregulated in lesioned neurons (Schober et al., 2001), yet neural functions of GDF-15 are still largely enigmatic. We have shown that GDF-15 acts as a survival promoting and protective factor for cultured embryonic and 6-hydroxydopaminelesioned adult dopaminergic neurons in the substantia nigra (Strelau et al., 2000), but dopaminergic neurons were not affected in GDF-15-deficient mice (our unpublished observations).

With the aim to reveal the physiological relevance of GDF-15 in promoting the survival of neurons, we have generated a GDF$15^{\text {lacZ/lac } Z}$ mouse. We have begun to analyze their motor, sensory, and sympathetic neurons, since these neuron populations have been paradigmatic in the discovery of other neurotrophic factors [e.g., neurotrophins, the CNTF family, FGF, GDNF (glial cell line-derived neurotrophic factor)] (Korsching, 1993; Sendtner et al., 1994; Li et al., 1995; Schober et al., 1999; Oberle et al., 2006). We report here that GDF-15-deficient mice exhibit progressive postnatal losses of spinal, facial, and trigeminal motoneurons, which reach a $\sim 20 \%$ maximal deficit at 6 months of age and are accompanied by significant impairment of motor skills. Sensory neurons in DRGs are also reduced by $20 \%$, whereas sympathetic neurons are not affected. Nevertheless, cultured motor, sensory, and sympathetic neurons all respond to GDF-15 by increased survival suggesting that loss of GDF-15 in vivo may be, in part, 
a
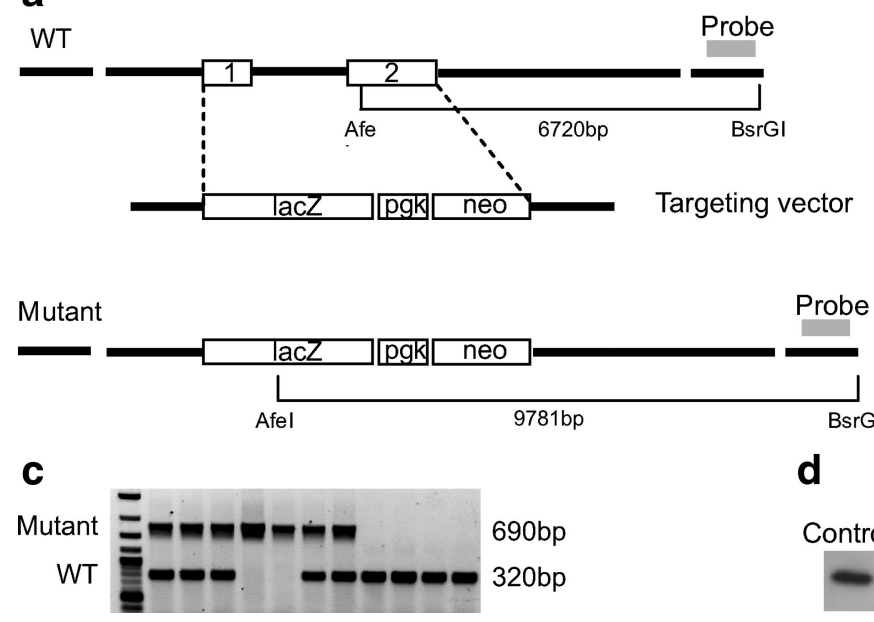

Figure 1. Targeting the GDF-15 gene and generation of GDF-15 ${ }^{-1-\text { lackknockin }}$ mice. $\boldsymbol{a}$, Structure of the GDF-15 gene and strategy for disrupting its structure. $\boldsymbol{b}, \boldsymbol{c}$, Southern blot and PCR analysis of tail DNA derived from the progeny of heterozygous mutant mice showing genotypes of wild-type, heterozygous, and GDF-15-deficient mice. $\boldsymbol{d}$, Western blot analysis of kidney protein extract from all genotypes tested with a peptide antibody against GDF- 15 confirms the absence of GDF- 15 in the knock-out mice and a gene- dosage effect of reduced protein levels in heterozygous mice. Five nanograms of recombinant GDF-15 were used as a control.

Table 1. Primer sequences for genotyping and Southern blot analysis

\begin{tabular}{llll}
\hline & Size & Forward & Reverse \\
\hline PCR & & & \\
$-1-$ & $690 \mathrm{bp}$ & $5^{\prime}$-CCC AGT CTT GTA GAC & $5^{\prime}$-CCC AGT CTT GTA GAC \\
& & AGA GCA A-3' & AGA GCA A-3' \\
$+1+$ & $320 \mathrm{bp}$ & $5^{\prime}$-ATG CGC ACC CAA & $5^{\prime}$-GGC CAC CAG GTC \\
& & GAG ACT-3' & ATC ATA AG-3' \\
Probe & $343 \mathrm{bp}$ & $5^{\prime}$-ACT GAT GGG GGA & 5' $^{\prime}$-TGC CCC ACC CAATAT \\
& & AAG AGG AG-3' & AAA GA-3' \\
\hline
\end{tabular}

compensated by other factors. GDF-15 is expressed in peripheral nerves, expressed and secreted by Schwann cells, and retrogradely transported in the adult sciatic nerve. Together, our data suggest that GDF-15 is a genuine novel trophic factor for motor and sensory neurons.

\section{Materials and Methods}

All animal experiments were approved by the Regierungspräsidium Karlsruhe and the local authorities at the University of Würzburg Heidelberg and/or the University of Nevada, Reno.

Targeting and generation of chimeric mice. The genomic phage used to construct the targeting vector contained a $21 \mathrm{~kb}$ insert spanning a region between two NotI restriction sites covering the complete GDF-15 gene. The replacement targeting vector pHM2 was a gift from Prof. Günther Schütz (German Cancer Research Center, Heidelberg, Germany) and described previously (Kaestner et al., 1994). A $1.7 \mathrm{~kb} 5^{\prime}$ untranslated promoter fragment of the GDF-15 gene was isolated and cloned $5^{\prime}$ from the lac $Z$ reporter gene into $\mathrm{pHM} 2$. Another $4.8 \mathrm{~kb}$ fragment covering the untranslated 3' end of the GDF-15 gene was connected $3^{\prime}$ to the neo cassette (Fig. 1a). After linearization with XhoI, the resulting DNA fragment was electroporated into D3 embryonic stem (ES) cells. ES clones were picked and screened for homologous recombination of the construct by PCR and subsequent Southern blot analysis as described. Targeted ES cells were injected into C57BL/6 blastocysts and transferred into the uteri of pseudopregnant $\mathrm{CD} 1$ recipient mothers. Chimeric offspring ES cell contributions ranged from 20 to $90 \%$ as judged by the proportion of agouti coat color. Homologous recombination in offspring of these mice was tested by Southern blot analysis after digestion of mouse tail DNA with AfeI and BsrGI. For the wild-type (wt) gene this resulted in a band of $6.7 \mathrm{~kb}$, for the combined gene in a band of $9.8 \mathrm{~kb}$ (Fig. 1b). A PCR b

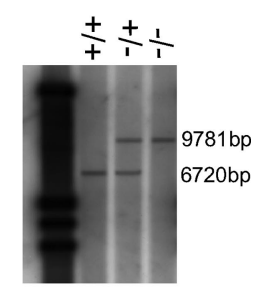

product was used as a probe. Recombination results in a deletion of a region spanning the complete coding sequence for GDF-15 as revealed by additional Western blot analysis (Fig. 1d).

PCR analysis. Total RNA was extracted from freshly prepared nerve tissue using Total RNA reagent (Biomol) according to the manufacturer's protocol. Three micrograms of RNA were reverse transcribed with MMLV-RT (Promega) in a $50 \mu \mathrm{l}$ reaction containing the manufacturer's buffer supplemented with $0.8 \mathrm{~mm}$ dNTPs and $0.02 \mu \mathrm{g} / \mu \mathrm{l}$ random hexanucleotides. Realtime quantitation of transcripts in cDNA samples was performed on an ABI PRISM 7000 Sequence Detection System using the corresponding TaqMan Assays-on-Demand Gene Expression Products (Applied Biosystems) and following the manufacturer's protocol. Results correspond to cDNA samples derived from three animals with each sample analyzed in triplicate. GAPDH, $18 \mathrm{~S}$ and $\beta$-Actin expression were considered as internal controls to which expression of genes of interest were normalized. Nonquantitative PCR was used for ES cell screenings and genotyping of GDF-15 mutant mice. Extracted genomic DNA was used for amplification in $50 \mu \mathrm{l}$ PCRs with specific forward and reverse primers (Table 1). Upstream and downstream primers used to synthesize a digoxygenated probe for Southern blot analysis according to the manufacturer (Roche) are listed in Table 1.

Gel electrophoresis and immunoblot analyses. Protein extracts were prepared by homogenizing mouse tissue in electrophoresis sample buffer, and the protein content was determined using densitometry (NIH ImageJ, version 1.61). Twenty-five micrograms of protein extract per lane were loaded on SDS-polyacrylamide gels and transferred to nitrocellulose membranes (Hybond ECL, GE Healthcare) by electroblotting. The membranes were incubated with purified polyclonal rabbit anti-rat GDF-15/MIC-1 antibody for $16 \mathrm{~h}$ at $4^{\circ} \mathrm{C}$. Bound antibody was detected with a peroxidase-conjugated secondary antibody and the ECL Western blotting substrate system (GE Healthcare) according to the manufacturer's manual. Samples of purified recombinant GDF-15 were visualized with Coomassie Blue and quantified by densitometry comparison with defined concentrations of protein standards using NIH Image (version 1.61) software.

Histology and neuron counts. Mice at different postnatal ages were transcardially perfused with $0.9 \%$ saline and $4 \%$ paraformaldehyde (PFA) according to a standard protocol (Oberle et al., 2006). Tissue samples were removed and postfixed overnight in $4 \%$ PFA. Samples were then placed in $15 \%$ sucrose for up to $24 \mathrm{~h}$ for cryoprotection and finally frozen on dry ice. Cryosections $(16 \mu \mathrm{m})$ were cut on a cryostat (CM 3050S, Leica) and mounted on chromalaun-precoated slides. Serial cryosections of the brainstem including the trigeminal and facial motor nuclei as well as lumbar spinal cord (L1-L6) were stained with cresyl violet or incubated with anti-mouse Islet-1 antibodies (1:100; Developmental Studies Hybridoma Bank, University of Iowa). Motoneuron profiles in both structures (brainstem and spinal cord) were counted on every third section. For dorsal root ganglia (DRG) and superior cervical ganglia (SCG) neuron count, tissues were fixed overnight in $4 \% \mathrm{PFA}$, rinsed with PBS and then transferred to $70 \%$ ethanol. Tissues were then processed through graded alcohols and xylenes and paraffin embedded. Serial $8 \mu \mathrm{m}$ sections were made throughout the length of the ganglia and Nissl stained. Only neuronal profiles with a visible nucleolus were counted. Cells were identified at $400 \times$ magnification by two independent examiners using the UTHSCSA Image Tool (IT) program. All counts were done blind to minimize observer bias. The total number was corrected for split cells according to Abercrombie's formula (Hedreen, 1998). For counts of axons in facial nerves of wild-type and GDF-15-deficient mice, semithin cross-sections of the nerves at the common trunk level, $\sim 1 \mathrm{~mm}$ 
to the stylomastoid foramen, were stained with toluidine blue and axon numbers of the surface area were counted using the UTHSCSA Image Tool (IT) program.

Neuron cultures. Dissociated cultures were prepared from postnatal day 1 (P1) mouse DRG and paravertebral sympathetic ganglia. The dissected ganglia were trypsinized $\left(0.25 \%\right.$ trypsin for $15 \mathrm{~min}$ at $\left.37^{\circ} \mathrm{C}\right)$ and dissociated by trituration. The neurons were grown in defined, serumfree medium on a polyornithine/laminin substratum in 96-well plates (2000 cells/well). Purified recombinant GDF-15 (R\&D Systems, Biopharm) was added to the cultures $1 \mathrm{~h}$ after plating when the cells had attached. After $24 \mathrm{~h}$ the cultures were fixed by addition of $0.25 \%$ glutaraldehyde in PBS. In another series of experiments DRG neurons were treated with NGF, BDNF, or NT-3 (PreproTech) $(10 \mathrm{ng} / \mathrm{ml}$ each) in combination with GDF-15 (10 ng/ml) for $48 \mathrm{~h}$, fixed, and counted. In a third series of experiments DRG neurons were pretreated with NGF (10 $\mathrm{ng} / \mathrm{ml}$ ) for $24 \mathrm{~h}$. Cultures were then washed and reincubated with blocking NGF antibodies (1:500; Millipore Bioscience Research Reagents) plus GDF-15 (10 ng/ml) for another $24 \mathrm{~h}$. Numbers of surviving neurons were determined by direct counting using phase contrast microscopy. Motoneurons of E13.5 mouse embryos were isolated and cultured as described previously (Wiese et al., 2001). After $7 \mathrm{~d}$ in vitro neurons were counted and data were analyzed using GraphPad Software Inc. Prism software.

Facial nerve transection and application of GDF-15. One-day-old mice were anesthetized by hypothermia on ice, and the right facial nerve was exposed as it exits from the foramen stylomastoideum and transected with microscissors. Then cytochrome $c$ (Sigma-Aldrich), or GDF-15 (5 $\mu \mathrm{g}$ each) was applied in a gel foam (Spongostan; Johnson \& Johnson). Wounds were sealed, and the animals recovered on a $37^{\circ} \mathrm{C}$ warm plate until they were returned to their mothers for $7 \mathrm{~d}$. After $7 \mathrm{~d}$, the brains were dissected for preparation of cryosections of the facial nuclei, Nissl stained, and counted as described above.

Immunocytochemistry. P5 mouse sciatic nerve was used as a source for primary Schwann cells and dissected and cultured as described (Honkanen et al., 2007). For immunocytochemistry, cultures were fixed in $4 \%$ PFA for 10 min and blocked in 10\% BSA and $0.1 \%$ Triton X-100 in $1 \times$ PBS for $1 \mathrm{~h}$. Cells were incubated with the following primary antibodies overnight at $4^{\circ} \mathrm{C}$ : anti-GDF-15 peptide antiserum (1:300) and monoclonal anti-S-100 (1:500, Millipore Bioscience Research Reagents). Cells were washed with $1 \times \mathrm{PBS}$ and incubated with Cy2- and Cy3-conjugated secondary antibodies (Vector Laboratories).

Rotarod. The rotarod apparatus 7650 (Ugo Basile) consists of a rubber covered cylindrical rod separated into five $6 \mathrm{~cm}$ sections by Plexiglas dividers. The starting rotation rate of the rod was $4 \mathrm{rpm}$ and was increased to $40 \mathrm{rpm}$ over $5 \mathrm{~min}$. Nine-month-old female mice $(n=15-/-$ and $+/+$ each) were placed on the rotarod apparatus and the timer was started. The time when the mouse fell from the rod was recorded with the maximum time being $300 \mathrm{~s}$. Each mouse was tested five times with a period of recovery of $45 \mathrm{~min}$. Results are given as the time that mice were able to maintain their balance on the rod. Supplemental Table 1 (available at www.jneurosci.org as supplemental material) shows supplemental data including latency time, body weight, and genotype for each animal. Genotyping was performed using tissue from tails of the animals. Statistical comparisons were performed using Student's $t$ test.

ELISA. A GDF-15-specific ELISA was used in accordance to the manufacturer protocol (R\&D Systems). Briefly, human primary Schwann cells were cultured in 24 -well plates (50,000 cells/well) for $24 \mathrm{~h}$. Subsequently a 24 -well plate $(100 \mu \mathrm{l} /$ well $)$ precoated with monoclonal antihuman GDF-15 (R\&D Systems) was used to incubate cell culture supernatants for $2 \mathrm{~h}$ at room temperature (RT). GDF-15 protein bound to the immobilized monoclonal antibody was incubated with a biotinylated polyclonal anti-human GDF-15 antibody (R\&D Systems) for $2 \mathrm{~h}$ at RT. Finally streptavidin-conjugated horseradish peroxidase was added and color change was measured. Protein concentrations in the culture medium was determined using dilution series of recombinant GDF-15 protein (R\&D Systems) for standards.

Iodination, injection, and nerve ligation for GDF-15 transport studies. Two approaches were used to test for axonal transport of radiolabeled GDF-15: direct nerve injection after sciatic nerve transection followed by autoradiography (Curtis et al., 1993; Leitner et al., 1999), and muscle injection, followed by gamma-counting of nerve segments of the ligated sciatic nerve. GDF-15 (from R\&D Systems) and neurotrophin-3 [(NT-3) from Regeneron] were radiolabeled with lactoperoxidase (von Bartheld, 2001) using ${ }^{125}$ I from PerkinElmer. Incorporations for GDF-15 were $73-81 \%$, with specific activities of $68-91 \mathrm{cpm} / \mathrm{pg}$, and $89 \%$ for NT-3, with a specific activity of $76 \mathrm{cpm} / \mathrm{pg}$. Adult C57BL/6 mice (a total of 12 mice for nerve injections) were anesthetized and a gelfoam patch with $0.1-0.3 \mu \mathrm{g}$ of radiolabeled GDF-15 was placed on the proximal stump of the transected sciatic nerve, followed $10 \mathrm{~h}$ later by perfusion-fixation and processing of dissected spinal cords and DRGs for autoradiography (von Bartheld, 2001). In another 14 adult mice, the sciatic nerve was ligated twice (1 mm apart) in the mid-gluteal region, using a 4.0 silk thread. Between 2 and $3 \mu \mathrm{l}$ of GDF-15 $(\sim 0.1-0.2 \mu \mathrm{g})$ or NT-3 $(\sim 0.1-0.2 \mu \mathrm{g})$ were injected with an insulin syringe into the right gastrocnemius muscle. In control mice, the sciatic nerve was transected distal to the ligatures, or trophic factors were injected into the gastrocnemius muscle without ligatures and without transection. Mice were anesthetized after $15 \mathrm{~h}$ and perfused with $4 \%$ paraformaldehyde through the heart. The injected leg muscle and the sciatic nerve as well as the same structures from the contralateral side were dissected and gamma-counted. The sciatic nerve was further dissected into three $\sim 1 \mathrm{~mm}$ segments distal and proximal to the ligatures and gamma-counted separately. The ligature threads were removed from the ligated nerve segments and all segments were gammacounted before and after dehydration in $70-100 \%$ ethanol to remove any free iodine. Data were pooled for experiments obtained from three to four independent experiments, normalized to the amount of radiolabeled protein that remained in the injection site at the time the animal was killed, and the data were graphed and evaluated for statistically significant differences between the transport and the control group (unpaired Student's $t$ test).

Statistical analysis. All data are presented as mean \pm SEM, and $n$ represents the number of animals used for each experiment. To determine statistical significance, we used the nonparametric two-tailed MannWhitney test (Prism5, GraphPad Software), which, unlike Student's $t$ test, does not depend on the assumption that the values follow a Gaussian distribution. Changes were identified as significant if the $p$ value was $<0.05$.

\section{Results}

\section{Targeting the GDF-15 gene and generation of GDF-15 -/-lacZknockin mice}

The mouse GDF-15 gene consists of two exons that are separated by one single intron within the coding region for the corresponding protein. To generate mice lacking the entire protein-coding sequence we targeted both exons. We provided a genetic marker of the mutation by placing the bacterial LacZ gene under the transcriptional regulatory control of the GDF-15 gene. Thus the integrity of the $5^{\prime}$ untranslated sequence was preserved in the targeted allele. The strategy for disrupting the GDF-15 gene is detailed in Material and Methods and in Figure 1. Southern blot and PCR analysis of tail DNA derived from the progeny of heterozygous mutant mice showed genotypes of wildtype, heterozygous and GDF-15-deficient mice (Fig. 1b,c). Western blot analysis, using equal amounts of kidney protein extracts from all genotypes with a peptide antibody against GDF-15, confirmed the absence of GDF-15 expression in the GDF-15 ${ }^{\text {lacZ/lac } Z}$ mice, and demonstrated a gene-dosage effect of reduced protein levels in heterozygous animals (Fig. 1d).

Homozygous null mice showed no obvious major abnormalities. The animals were viable, fertile, and indistinguishable from wild-type littermates with respect to movement and other behavioral characteristics. Consistent with the observation that mice overexpressing GDF-15 show hypophagia and reduced body weight (Johnen et al., 2007), body weight of adult female GDF15 -deficient mice was significantly increased by $16 \%(p=0.003)$ 

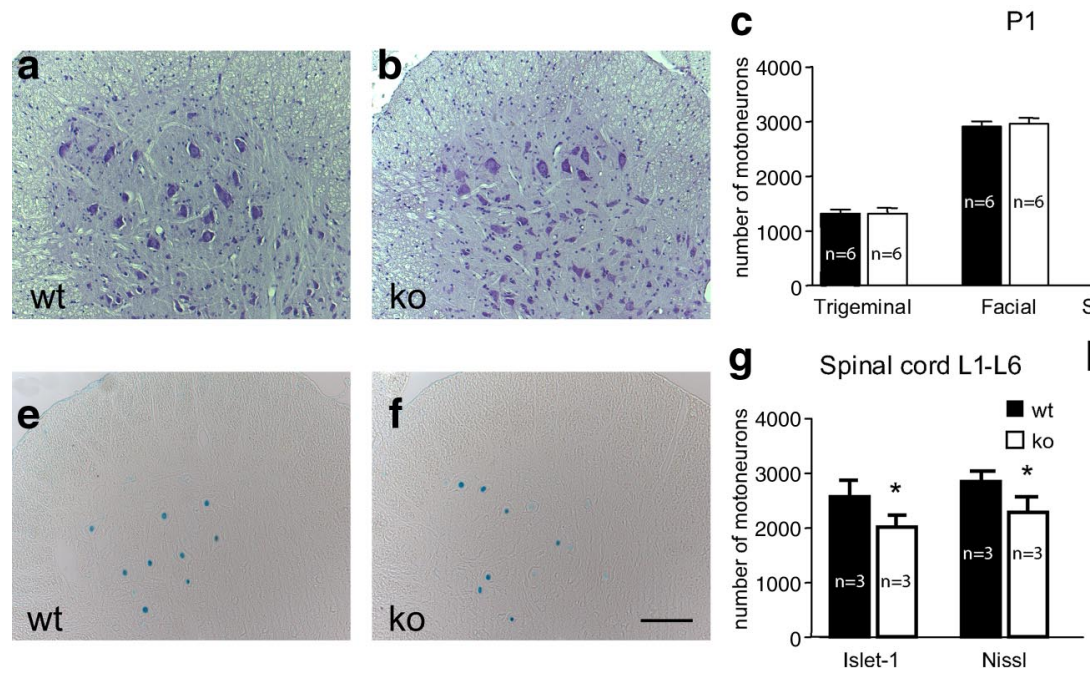

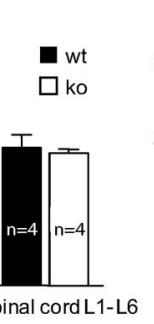

h

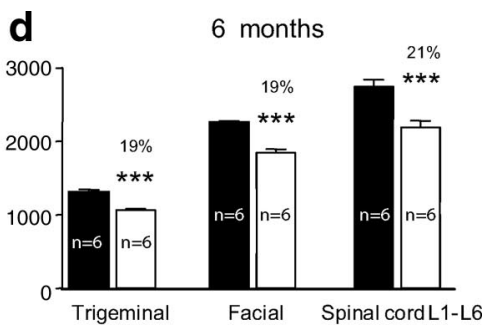

Facial nucleus

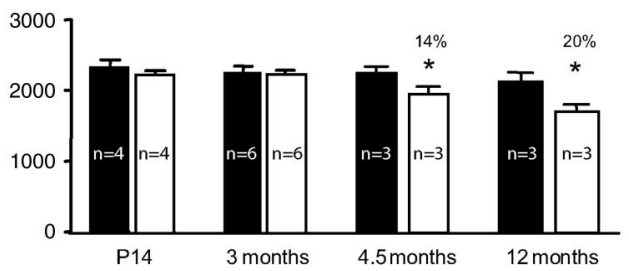

Figure 2. Quantitative determinations of motoneuron numbers at different postnatal time points. $\boldsymbol{a}, \boldsymbol{b}$, Wild-type and knock-out spinal cord sections (anterior horn) were stained with cresyl violet. $c$, Counts of trigeminal, facial, and ventral spinal cord motoneurons at P1 reveal that numbers in GDF-15-deficient mice and wild-type littermates were not significantly different. $\boldsymbol{d}$, Significant losses of trigeminal, facial, and spinal cord motoneurons in GDF-15-deficient mice, compared with wild-type littermates at 6 months of age. $\boldsymbol{e}$, $\boldsymbol{f}$, Wild-type and knock-out spinal cord sections (anterior horn) immunostained with Islet-1 antibodies. Scale bar, $100 \mu \mathrm{m} . \boldsymbol{g}$, Control experiments confirm comparable losses of Nissl- and Islet-1-stained motoneurons in spinal cord sections of knock-out compared with wt mice at 6 months. $\boldsymbol{h}$, Temporal development of losses of facial motoneurons in GDF-15-deficient mice reveals a significant decrease from 4.5 months onward and a plateau between 6 and 12 months of age.

(female wild-type littermates $31 \pm 5.2 \mathrm{~g}, n=15$, vs female GDF$15^{\text {lacZ/lacZ }}, 36 \pm 5.3 \mathrm{~g}, n=15$ ).

\section{Loss of motoneurons in spinal cord and brainstem motor nuclei of GDF-15-deficient mice occurs between 3 and 6 months}

Developing motoneurons depend on multiple muscle- and Schwann cell-derived proteins for their survival (Calof and Reichardt, 1984; Dohrmann et al., 1986; Oppenheim et al., 1988, 2001; Arakawa et al., 1990; Sendtner et al., 2000). We therefore investigated first whether lack of GDF-15 affected the extent of programmed cell death (PCD) of lumbar spinal and selected brainstem motoneurons. As shown in Figure $2 c$, numbers of motoneurons in trigeminal and facial nuclei, and in spinal cord L1-L6 did not significantly differ between GDF-15 mutant mice and wt littermates at P1. These results show that GDF-15 is not an essential trophic survival factor for motoneurons during the period of PCD.

As motoneurons mature, their biological properties change, and whereas many developing motoneurons die during the period of PCD, death prevention (maintenance) is a hallmark of the mature system. Several factors have been identified that are required for maintaining normal numbers of postnatal motoneurons, including CNTF and LIF (Masu et al., 1993; Sendtner et al., 1996). Therefore, we next investigated whether GDF-15 deficiency resulted in alterations of motoneuron numbers in adult GDF-15 knock-out mice. As shown in Figure 2, $a, b$, and $d$, GDF-15 null mice at the age of 6 months revealed a significant $19 \%$ cell loss of trigeminal and facial motoneurons, whereas $21 \%$ of lumbar spinal motoneurons were lost. These data suggest that GDF-15 is required for the maintenance of a significant fraction of adult motoneurons. To determine the temporal sequence of motoneuron losses we analyzed the facial nucleus from P14 to 12 months of age. Figure $2 h$ reveals that numbers of facial motoneurons were not different in GDF-15 mutant mice and wt littermates at P14 and 3 months of age. At 4.5 months, GDF-15 mutant mice exhibited a significant $14 \%$ motoneuron loss in the facial nucleus, which further increased at 6 months, reaching a stable plateau thereafter until 12 months. Staining for Islet-1 (Fig. 2e,f) confirmed the results obtained from Nissl-stained sections. Morphometric analyses of the remaining motoneurons in 6-monthold GDF-15-deficient mice revealed no detectable differences with respect to size, nuclear and cytoplasmic areas as well as Nissl morphology compared with GDF-15 +/+lacZknockin littermates (data not shown).

To assess whether loss of facial motoneurons in GDF$15^{-/- \text {lacZknockin }}$ mice correlates with reduced numbers of myelinated motor axons in the peripheral facial nerve, we analyzed cross-sections of facial nerves at the level of the foramen stylomastoideum in GDF-15 mutant mice and GDF-15 + +lacZknockin littermates at 6 months. As shown in Fig. 3a, GDF-15-deficient mice revealed a $13 \%(p<0.05)$ loss in myelinated axons compared with wild-type littermates. The difference in axon and cell body losses can be explained by the stapedius nerve fibers leaving the facial nerve inside the facial canal.

Postnatal neuron losses are often accompanied by local accumulations of inflammatory cells, including activated microglial cells (Dheen et al., 2007). However, immunohistological analyses using antibodies against the microglia/macrophage marker CD68 did not reveal an increase of activated microglial cells in the lumbar spinal cord or the facial nuclei at the age of 6 months (data not shown).

Lack of GDF-15 also results in losses of dorsal root ganglionic sensory neurons, but does not affect numbers of sympathetic neurons in the superior cervical ganglion

Numerous trophic factors support both motoneurons and other neuron populations, e.g., DRG sensory neurons. We therefore next determined numbers of neurons in the DRGs L4 and L5 at 6 months. As shown in Figure 3c, numbers of neurons in L4 and L5 DRGs of GDF-15-deficient mice were significantly reduced by $22 \%(p<0.05)$ and 25\% $(p<0.01)$, respectively, compared with wild-type littermates. In contrast to motor and sensory neuron losses, we found no difference in the number of SCG sympathetic neurons between wild-type and GDF-15 null mice (Fig. 3b). 

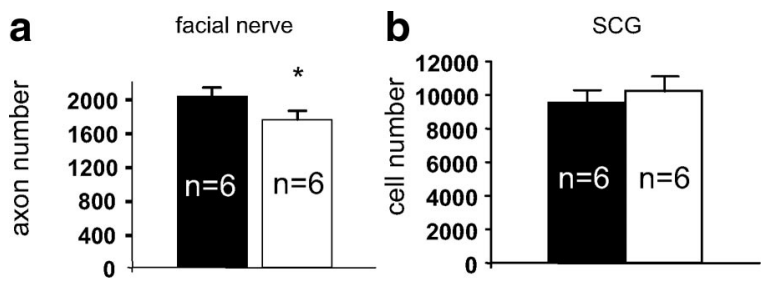

C

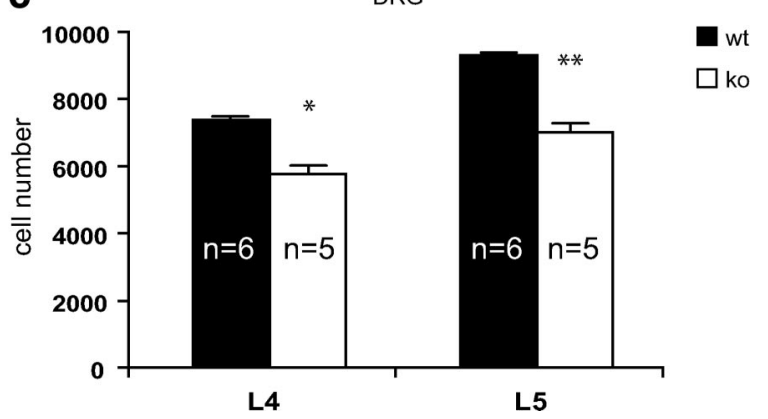

Figure 3. Analysis of facial nerve axon, DRG, and sympathetic neuron (SCG) numbers in GDF-15-deficient mice and wild-type littermates at 6 months of age. $\boldsymbol{a}$, Significant $13 \%$ decrease of axon numbers in the facial nerve of GDF-15-deficient mice, compared with wild-type littermates. $\boldsymbol{b}$, Numbers of neurons in the SCG of GDF-15-deficient mice and wild-type littermates are not significantly different. c, Significant neuron losses in L4 (-2\%) and L5 (-5\%) DRG in GDF-15-deficient mice compared with wild-type littermates.

\section{Impairment of rotarod skills}

Consistent with motor and sensory neuron deficiencies, GDF-15 mutant mice showed a significantly impaired (supplemental Table 1, available at www.jneurosci.org as supplemental material; $p<0.01)$ ability to remain on an accelerating rotarod (137 s), compared with GDF-15 $5^{+/+ \text {lacZknockin }}$ littermates (186 s) with a $p$ value $<0.0068$.

\section{GDF-15 prevents cell death of cultured motor, sensory,} and sympathetic neurons

Having shown that distinct types of neurons are differentially affected in GDF-15 mutant mice, we next investigated putative in vitro responses of these neuron populations to GDF-15. As shown in Figure 4, embryonic (E13.5) motor (Fig. 4a,b) as well as neonatal DRG (Fig. 4c) and sympathetic neurons (Fig. $4 d$ ) responded to GDF-15 in a dose-dependent manner with increased survival. For motor neurons the $\mathrm{ED}_{50}$ was $0.85 \mathrm{pg} / \mathrm{ml}$ supporting the notion (Strelau et al., 2000) that GDF-15 is a very potent neurotrophic factor. CNTF, when added to GDF-15 (10 ng each) (Fig. 4b) did not significantly increase motoneuron survival suggesting that both factors address identical or largely overlapping populations of motoneurons. With regard to DRG neurons, GDF-15 (10 $\mathrm{ng} / \mathrm{ml}$ ) did not significantly increase neuron survival when added to saturating concentrations of NGF, BDNF, or NT-3 (data not shown). When DRG neurons were pretreated for $24 \mathrm{~h}$ with NGF $(10 \mathrm{ng} / \mathrm{ml})$, and then washed and reincubated with NGF blocking antibodies (1:100) together with GDF-15 (10 ng/ml), the survival effect elicited by GDF-15 was not significantly greater than without an NGF pretreatment (data not shown).

GDF-15 decreases neuron death after facial nerve transection To investigate whether GDF-15 was also able in vivo to protect axotomized neurons we transected the facial nerve in $\mathrm{P} 1$ mice and applied cytochrome $c$ or GDF-15, respectively, to the proximal nerve stump. After $7 \mathrm{~d},>85 \pm 3 \%$ of facial motoneurons were lost on the lesion side in cytochrome $c$-treated mice $(n=5)$. Local application of GDF-15 $(n=6)$ resulted in a loss of only $66 \%$ of motoneurons, thus with GDF-15 applied, $34 \pm 4.5 \%$ of the lesioned motoneurons survived ( $p=0.010$ ) as opposed to $15 \%$ in the control condition, supporting the notion that GDF-15 is also a potent neurotrophic factor in vivo.

GDF-15 is more abundant in adult peripheral nerve than in striated muscle and synthesized by Schwann cells

Striated muscle and peripheral nerve are considered to be principal sources of trophic factors required by motoneurons. We therefore determined and compared GDF-15 mRNA levels in the sciatic nerve and the gastrocnemius muscle at different postnatal ages in wild-type mice. Normalized to the lowest GDF-15 expression level at P1, GDF-15 mRNA expression in the sciatic nerve increased 24-fold from P1 to P180 (Fig. 5a). GDF-15 mRNA levels in the gastrocnemius muscle increased in parallel from P1 to $\mathrm{P} 14$, but subsequently returned to $\mathrm{P} 1$ levels. The inverse quantitative development of GDF-15 mRNA in nerve and muscle subsequent to P14, and the death of GDF-15-deprived motoneurons between 3 and 6 months, when GDF-15 increases prominently in wild-type nerve, suggest that the nerve may be an important source of GDF-15.

Attempts to localize the cellular distribution and presumptive source(s) of GDF-15 in adult peripheral nerve by immunostaining for $\beta$-Gal or GDF-15 in situ failed to reveal a specific signal. However, dissociation of adult mouse sciatic nerve and maintaining the cells in culture for 4 weeks revealed intense GDF-15 immunoreactivity in S100-positive cells (Fig. $6 a-d$ ), suggesting localization of GDF-15 in Schwann cells. Similarly, cultured human adult Schwann cells stained positively for GDF-15 (data not shown). To further verify Schwann cells as a principal source of GDF-15 protein, we determined levels of GDF-15 protein by ELISA. Figure $6 e$ reveals that cultures of human Schwann cells contain high levels of GDF-15 regardless of the amount of serum present in the culture medium. Together, these data suggest that (lesioned) Schwann cells are an important source of GDF-15 in peripheral nerve, and that they express and secrete GDF-15 (Fig. 6e,f).

Expression of neurotrophic factors in GDF-15-deficient mice Both the postnatal onset and the magnitude of motor and sensory neuron losses seen in GDF-15 mutant mice strikingly resemble the CNTF knock-out phenotype (Masu et al., 1993). Furthermore, both GDF-15 and CNTF are apparently synthesized by and released from Schwann cells (Manthorpe et al., 1986; Sendtner et al., 1992). We therefore considered the possibility that the GDF-15 knock-out phenotype might be caused by a loss of CNTF and determined levels of mRNAs for CNTF and other growth factors known to be relevant to motor and sensory neuron survival in the sciatic nerve. Figure $5 b$ indicates that levels of CNTF mRNA in sciatic nerves from wild-type and GDF-15 mutant mice were similar, excluding the possibility that the GDF-15 knockout phenotype results from a loss of CNTF in peripheral nerve. Furthermore, levels of LIF, CT-1, BDNF, NT-3, GDNF, TGF- $\beta 1$, and TGF $\alpha$ mRNAs did not significantly differ in sciatic nerves from wild-type and GDF-15 mutant mice. It is therefore unlikely that quantitative changes in the expression of any of these factors in GDF-15-deficient mice may account for the GDF-15 mutant phenotype.

Evidence for retrograde axonal transport of GDF-15 in ligated adult sciatic nerve

To determine whether GDF-15 can be transported retrogradely along axons, we measured the transport of radiolabeled GDF-15 


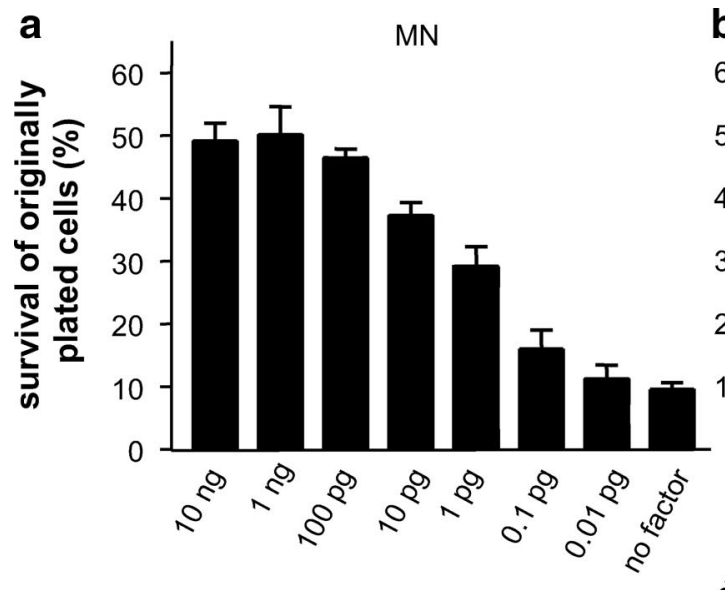

C

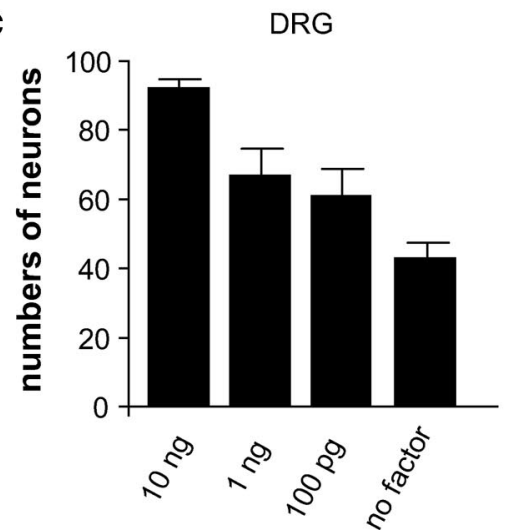

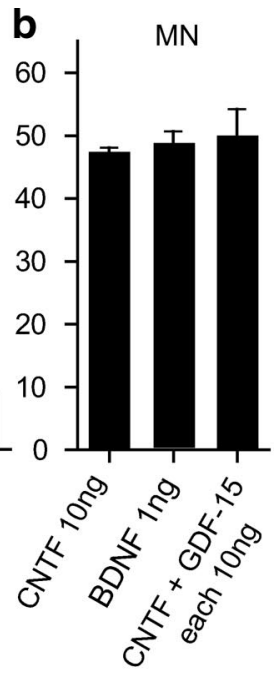

d $\quad S G$

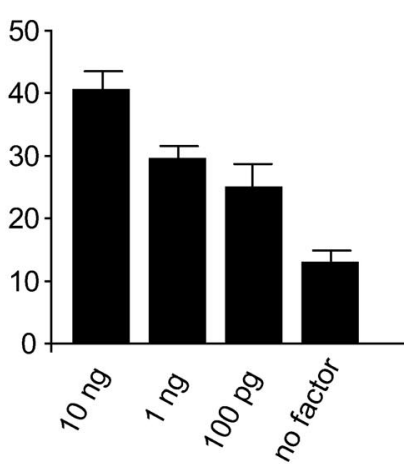

Figure 4. Survival of cultured wt mouse neurons in the presence of different concentrations of GDF-15. $\boldsymbol{a}, \boldsymbol{b}$, Percentage of originally plated embryonic (E13.5) motoneurons (MN) after $7 \mathrm{~d}$ in vitro. $\boldsymbol{c}, \boldsymbol{d}$, Numbers of neurons isolated from P1 paravertebral sympathetic ganglia (SG) and DRGs after $24 \mathrm{~h}$ in vitro.
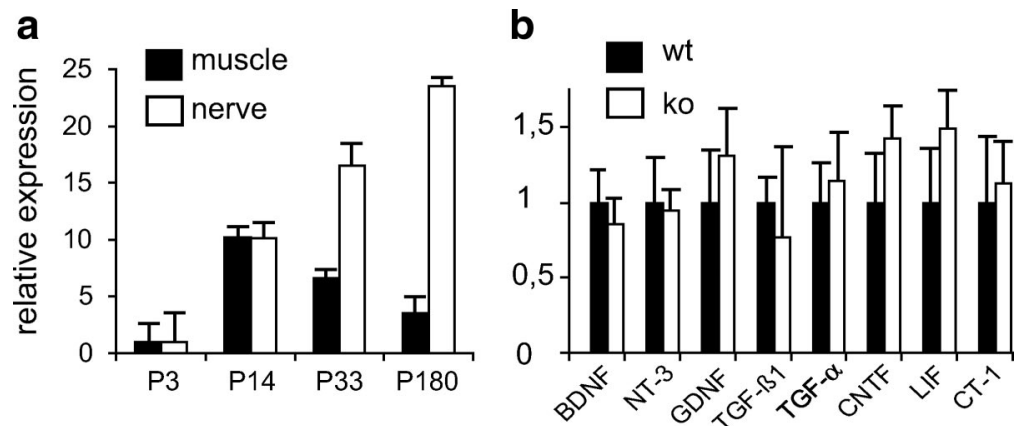

Figure 5. $\boldsymbol{a}, \boldsymbol{b}$, Expression of GDF-15 mRNA in sciatic nerve versus gastrocnemius muscle ( $\boldsymbol{a})$, and of trophic factor mRNAs in sciatic nerve $(\boldsymbol{b})$ of 6-month-old GDF-15-deficient mice and wild-type littermates.

applied to transected sciatic nerves of wild-type mice by autoradiography as well as accumulation of radiolabeled GDF-15 distal to ligatures of the sciatic nerve in adult mice injected into the gastrocnemius muscle. Although we failed to observe retrograde transport from injections into transected nerves to DRGs or motoneurons in the spinal cord (data not shown), we observed significant accumulation and transport of GDF-15 in ligated sciatic nerves. In the ligation experiments, NT-3 was used as a positive control, since it is known to be transported retrogradely in the sciatic nerve (Matheson et al., 1997). As shown in Figure 7, $a$ and $b$, the nerve segment distal to the first ligation contained 3-4

times as many cpm ( $\sim 3-4$ pg of GDF-15) compared with the proximal segment. This amount is significantly above the threshold limit of detection $(\sim 40 \mathrm{cpm}=$ $0.35 \mathrm{pg}$ ). The accumulation of GDF-15 was not due simply to proximity of the injection site, because no gradient was apparent in most of the sciatic nerve in the absence of ligatures (Fig. 7c). To ascertain that the GDF-15 had accumulated distal to the ligature as a result of axonal transport (as opposed to simple systemic diffusion), the sciatic nerve was transected $\sim 3$ $\mathrm{mm}$ distal to the first ligature in a group of control mice. In those controls, there was no accumulation of GDF-15 in the distal segments, providing evidence that most of the accumulated GDF-15 in front of the ligature in the sciatic nerve arrived there by axonal transport (Fig. $7 b$ ). We obtained similar data for radiolabeled NT-3, consistent with its known transport along the sciatic nerve (Matheson et al., 1997). The amount of GDF-15 that is transported $(3-4 \mathrm{pg})$ appears to be similar to that of NT-3 (data not shown). We conclude that GDF-15 can be retrogradely transported along adult sciatic nerve axons, consistent with its trophic effect on motoneurons.

\section{Discussion}

Here we show that GDF-15, a distant member of the TGF- $\beta$ superfamily (Bootcov et al., 1997; Böttner et al., 1999a), is a potent trophic factor for adult motor and DRG sensory neurons. In addition to CNTF (Masu et al., 1993) and CNTF in cooperation with LIF (Sendtner et al., 1996), GDF-15 is the second factor shown by gene knock-out to be required to maintain adult motoneurons. Within the TGF- $\beta$ superfamily, only signaling via the common GDNF subfamily receptor c-ret (Kramer et al., 2007) has so far been shown to be involved in the maintenance of adult neurons, i.e., aged midbrain dopaminergic neurons.

Several features of the GDF-15 knockout resemble the CNTF knock-out phenotype, and several biological properties of CNTF and GDF- 15 are similar. Resembling GDF-15 knock-out mice, CNTFdeficient mice show normal numbers of facial motoneurons at 4 weeks, but significant losses at 28 weeks. In terms of magnitude, facial motoneuron losses in GDF-15- and CNTF-deficient mice are nearly identical (GDF-15, $-19 \%$; CNTF, $-22 \%$ ). As in the case of CNTF (Stöckli et al., 1989), the principal source of GDF-15 seems to be the peripheral nerve and in particular the (lesioned) Schwann cell. Levels of both CNTF (Stöckli et al., 1989; Dobrea et al., 1992) and GDF-15 are low in newborn and early postnatal sciatic nerve and do not reach adult levels until the fourth postnatal week. Thus, expression of both CNTF and 


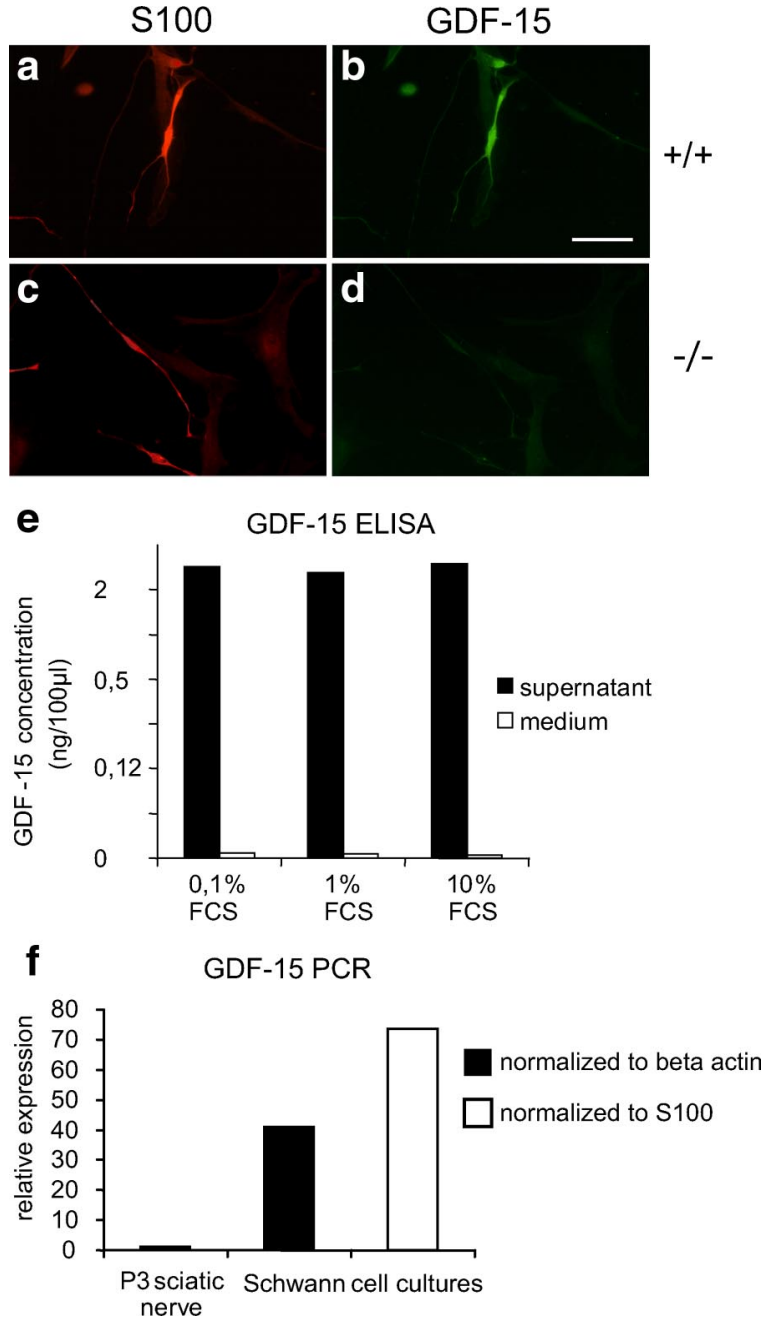

Figure 6. GDF-15 expression and secretion by Schwann cells. $\boldsymbol{a}-\boldsymbol{d}$, Adult Schwann cells isolated from 6-month-old mouse sciatic nerve reveal immunoreactivity for GDF-15. Scale bar, $50 \mu \mathrm{m}$. $\boldsymbol{e}$, Release of GDF-15 from adult human Schwann cells in culture. $\boldsymbol{f}$, GDF-15 mRNA expression determined by real-time quantitative $\mathrm{PCR}$ and normalized against $\beta$-actin or $\mathrm{S} 100$.

GDF-15 seems to parallel the differentiation of Schwann cells in the nerve (Jessen and Mirsky, 1992). However, whereas CNTF immunoreactivity is very prominent in adult Schwann cells in situ but drastically downregulated in cultured Schwann cells (Sendtner et al., 1994), the reverse seems to be true for GDF-15. The mechanisms underlying regulation of GDF-15 both in cultured Schwann cells and, possibly, in peripheral nerve lesions, are still elusive. Whether GDF-15 expression and/or release may be controlled by CNTF needs to be addressed in further studies. CNS lesion studies have revealed a dramatic induction of GDF-15 mRNA mostly in neurons and to a minor extent in microglial cells (Schober et al., 2001). In contrast, in the unlesioned CNS, similar to the intact peripheral nerve, GDF-15 mRNA and immunoreactivity are virtually undetectable (except in the choroid plexus) (Strelau et al., 2000). Although this pattern of regulation might suggest a role for GDF-15 as a "lesion factor," the notion of CNTF as a lesion factor (Sendtner et al., 1994) has been primarily based on the lack of a signal sequence in the molecule, making its mode of release difficult to understand. GDF-15, however, has a signal sequence, suggesting that it may be released by classical secretory pathways.

Populations of motoneurons maintained by GDF-15 and CNTF seem to be identical or largely overlapping, since com- a

|125_GDF-15 transport
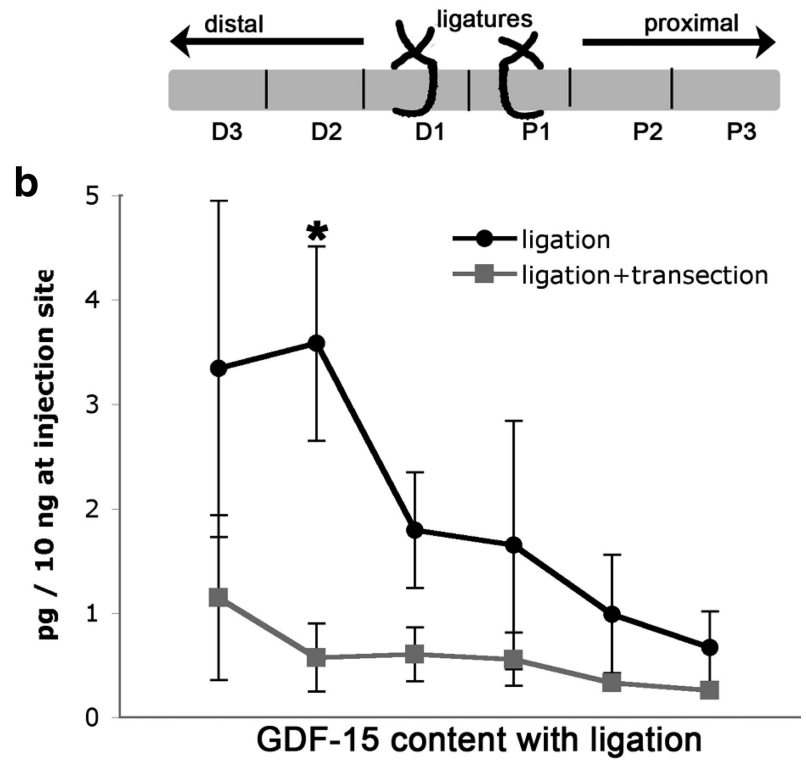

C

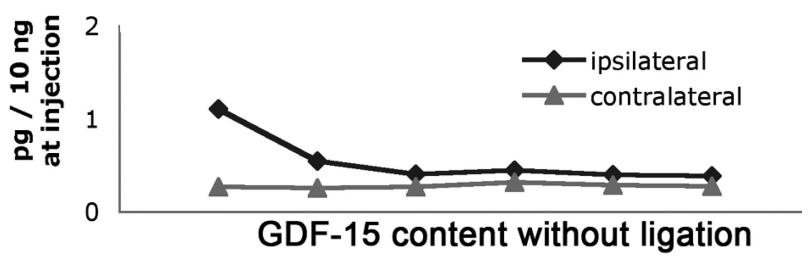

Figure 7. Evidence for axonal transport of GDF-15 by ligation of the sciatic nerve of adult mouse. $\boldsymbol{a}$, Schematic image of the sciatic nerve and its distal and proximal segments adjacent to a double ligation at the mid-gluteal region. D, Distal, P, proximal; DI, distal ligature, $\mathrm{PI}$, proximal ligature. $\boldsymbol{b}$, Accumulation of radiolabeled GDF-15 in the ligated sciatic nerve $15 \mathrm{~h}$ after injection of $\sim 100-200 \mathrm{ng}$ of radiolabeled GDF-15 into the gastrocnemius muscle. The amounts in the sciatic nerve segments (picograms, normalized to $10 \mathrm{ng}$ in the injection site at time the animal was killed) are plotted as a function of distance along the sciatic nerve as indicated in $\boldsymbol{a}$. Black circles, GDF-15 in sciatic nerve with ligatures $(n=4)$; gray squares, GDF-15 in sciatic nerve with ligatures and distal transection to abolish axonal transport $(n=3)$. Error bars, SEM. Statistical significance is indicated by ${ }^{*} p<0.025$. $\boldsymbol{c}$, Amounts of radiolabeled GDF-15 are plotted as in $\boldsymbol{b}$ for a sciatic nerve without ligation or transection (black diamonds), compared with the control side (gray triangles). Note the lack of a significant gradient from distal to proximal segments.

bined application of the two factors in vitro did not significantly increase survival beyond neuron numbers supported by each single factor. With regard to sensory neurons the effect of GDF-15 is modest, but significant. GDF-15 does not significantly increase neuron survival elicited by any of the neurotrophins, suggesting again that DRG neurons maintained by GDF-15 are contained within the neurotrophin-responsive subpopulations. This notion is further supported by the analysis of trkA-, trkB-, and trkCpositive neurons (in situ hybridization in 6 months-old GDF-15 knock-out mice), which revealed that all subpopulations are proportionally affected by the $\sim 20 \%$ neuron loss (V. Hagel, J. Strelau, and K. Unsicker, unpublished observations).

Some growth factors such as CNTF (Curtis et al., 1993) are poorly transported axonally, whereas others are very efficiently transported retrogradely along axons (Matheson et al., 1997; Rind et al., 2005). To determine whether GDF-15 is axonally transported, we pursued two strategies: direct application of radiolabeled GDF-15 to the transected sciatic nerve stump (Leitner et al., 1999) followed by autoradiography of DRGs and spinal cord sections, and measurement of accumulation of radiolabeled 
GDF-15 distal to a sciatic nerve ligation. Although we did not find GDF-15 by autoradiography in the DRGs and spinal cord, possibly because of too low amounts transported or too short (10 h) transport duration, GDF-15 accumulated by axonal transport in front of a ligature of the sciatic nerve (Fig. $7 b$ ). Axonal transport of GDF-15 may be age- and nerve-dependent, since GDF-15 transport was very weak or absent in the hypoglossal nerve of neonatal rat pups (Rind et al., 2005) (C. S. von Bartheld, J. Strelau, and K. Unsicker, unpublished observations). The finding of robust axonal transport in the ligated adult sciatic nerve places GDF-15 among the neurotrophic factors which are efficiently transported retrogradely from their target along axons and explains how the trophic signal is delivered to the cell bodies. The prominent protective effect of GDF-15 on axotomized facial neurons adds to previous evidence showing a neurotrophic role of GDF-15 for lesioned dopaminergic neurons in the substantia nigra (Strelau et al., 2000).

We found, however, that numbers of dopaminergic neurons in the substantia nigra of GDF-15-deficient mice are normal (our unpublished observations). Therefore, the putative relevance of GDF-15 for neurons in the CNS remains to be investigated.

The present study underscores the physiological importance of GDF-15 for neuron populations other than motoneurons, i.e., sensory neurons in spinal ganglia, which are also dependent on CNTF (Horton et al., 1996). Despite many similarities in the GDF-15 and CNTF knock-out phenotypes, there are also distinct differences. For example, we did not find an increase in microglial cells in GDF-15 mutant mice, in contrast to the CNTF-deficient mice (Masu et al., 1993).

The significant overlap in GDF-15 and CNTF properties and knock-out phenotypes raises questions: whether the two factors may also cooperate in functional terms and what might be other components of a cooperative network. The GDF-15/CNTF double knock-out may generate answers in terms of cooperativity of the two factors in the regulation of neuron survival. The fact that the two factors are members of two multifunctional and contextually acting cytokine families, the TGF- $\beta$ and the CNTF/neurokine families, includes the potential for a much broader spectrum of putative coordinated roles. This notion is also supported by the fact that GDF-15 and members of the TGF- $\beta$ s, depending on context, may signal both cell survival and death (Krieglstein et al., 1998, 2000; Strelau et al., 2000; Baek et al., 2001).

Studies on putative mechanisms, by which GDF-15 promotes motor and sensory neuron survival, are hampered, in part, by the lack of knowledge about the GDF-15 receptor, which seems to belong neither to the TGF- $\beta$ serine/threonine kinase receptors nor to the c-ret/GFR $\alpha$ receptors of the GDNF subfamily (H. Peterziel, personal communication). Demonstration of retrograde transport of GDF-15 substantiates its role as a neurotrophic factors, although other neurotrophically acting factors, such as FGF-2 and TGF- $\beta$, are not retrogradely transported (Ferguson et al., 1991; Hendry and Crouch, 1991). In addition to a direct role in promoting neuron survival GDF-15 may induce expression of Schwann- or immune cell-derived factors others than those quantified by us, or may stimulate or inhibit their release at the level of the protein, which may eventually protect motor and sensory neurons. The responses of cultured neonatal motor, sensory, and sympathetic neurons to GDF-15 suggest that they express GDF-15 receptors and that, in vivo, loss of GDF-15 may be compensated by other factors yet to be identified.

In conclusion, our study indicates a physiological and significant role of GDF-15 in the maintenance of adult motor and sensory neurons. Whether GDF-15, with its previously demon- strated potential in animal models of Parkinson's disease (Strelau et al., 2000) and the present demonstration of its implication in motor and sensory neuron maintenance, holds promises for the treatment of motoneuron or other neurodegenerative diseases, awaits further study.

\section{References}

Arakawa Y, Sendtner M, Thoenen H (1990) Survival effect of ciliary neurotrophic factor (CNTF) on chick embryonic motoneurons in culture: comparison with other neurotrophic factors and cytokines. J Neurosci 10:3507-3515.

Baek SJ, Kim KS, Nixon JB, Wilson LC, Eling TE (2001) Cyclooxygenase inhibitors regulate the expression of a TGF-beta superfamily member that has proapoptotic and antitumorigenic activities. Mol Pharmacol 59:901-908.

Bootcov MR, Bauskin AR, Valenzuela SM, Moore AG, Bansal M, He XY, Zhang HP, Donnellan M, Mahler S, Pryor K, Walsh BJ, Nicholson RC, Fairlie WD, Por SB, Robbins JM, Breit SN (1997) MIC-1, a novel macrophage inhibitory cytokine, is a divergent member of the TGF-beta superfamily. Proc Natl Acad Sci U S A 94:11514-11519.

Böttner M, Suter-Crazzolara C, Schober A, Unsicker K (1999a) Expression of a novel member of the TGF-beta superfamily, growth/differentiation factor-15/macrophage-inhibiting cytokine-1 (GDF-15/MIC-1) in adult rat tissues. Cell Tissue Res 297:103-110.

Böttner M, Laaff M, Schechinger B, Rappold G, Unsicker K, Suter-Crazzolara C (1999b) Characterization of the rat, mouse, and human genes of growth/ differentiation factor-15/macrophage inhibiting cytokine-1 (GDF-15/MIC1). Gene 237:105-111.

Calof AL, Reichardt LF (1984) Motoneurons purified by cell sorting respond to two distinct activities in myotube-conditioned medium. Dev Biol 106:194-210.

Curtis R, Adryan KM, Zhu Y, Harkness PJ, Lindsay RM, DiStefano PS (1993) Retrograde axonal transport of ciliary neurotrophic factor is increased by peripheral nerve injury. Nature 365:253-255.

Dheen ST, Kaur C, Ling EA (2007) Microglial activation and its implications in the brain diseases. Curr Med Chem 14:1189-1197.

Dobrea GM, Unnerstall JR, Rao MS (1992) The expression of CNTF message and immunoreactivity in the central and peripheral nervous system of the rat. Brain Res Dev Brain Res 66:209-219.

Dohrmann U, Edgar D, Sendtner M, Thoenen H (1986) Muscle-derived factors that support survival and promote fiber outgrowth from embryonic chick spinal motor neurons in culture. Dev Biol 118:209-221.

Fairlie WD, Moore AG, Bauskin AR, Russell PK, Zhang HP, Breit SN (1999) MIC-1 is a novel TGF-beta superfamily cytokine associated with macrophage activation. J Leukoc Biol 65:2-5.

Ferguson IA, Schweitzer JB, Bartlett PF, Johnson EM Jr (1991) Receptormediated retrograde transport in CNS neurons after intraventricular administration of NGF and growth factors. J Comp Neurol 313:680-692.

Hedreen JC (1998) Lost caps in histological counting methods. Anat Rec 250:366-372.

Hendry IA, Crouch MF (1991) Retrograde axonal transport of the GTPbinding protein $\mathrm{Gi}$ alpha: a potential neurotrophic intra-axonal messenger. Neurosci Lett 133:29-32.

Honkanen H, Lahti O, Nissinen M, Myllylä RM, Kangas S, Päiväläinen S, Alanne MH, Peltonen S, Peltonen J, Heape AM (2007) Isolation, purification and expansion of myelination-competent, neonatal mouse Schwann cells. Eur J Neurosci 26:953-964.

Horton AR, Davies AM, Buj-Bello A, Bartlett P, Murphy M (1996) Leukemia inhibitory factor and ciliary neurotrophic factor in sensory neuron development. Perspect Dev Neurobiol 4:35-38.

Hromas R, Hufford M, Sutton J, Xu D, Li Y, Lu L (1997) PLAB, a novel placental bone morphogenetic protein. Biochim Biophys Acta 1354:40-44.

Jessen KR, Mirsky R (1992) Schwann cells: early lineage, regulation of proliferation and control of myelin formation. Curr Opin Neurobiol 2:575-581.

Johnen H, Lin S, Kuffner T, Brown DA, Tsai VW, Bauskin AR, Wu L, Pankhurst G, Jiang L, Junankar S, Hunter M, Fairlie WD, Lee NJ, Enriquez RF, Baldock PA, Corey E, Apple FS, Murakami MM, Lin EJ, Wang C, et al (2007) Tumor-induced anorexia and weight loss are mediated by the TGF-beta superfamily cytokine MIC-1. Nat Med 13:1333-1340.

Kaestner KH, Montoliu L, Kern H, Thulke M, Schütz G (1994) Universal $\beta$-galactosidase cloning vectors for promoter analysis and gene targeting. Gene 148:67-70. 
Korsching S (1993) The neurotrophic factor concept: a reexamination. J Neurosci 13:2739-2748.

Kramer ER, Aron L, Ramakers GM, Seitz S, Zhuang X, Beyer K, Smidt MP, Klein R (2007) Absence of Ret signaling in mice causes progressive and late degeneration of the nigrostriatal system. PLoS Biol 5:e39.

Krieglstein K, Henheik P, Farkas L, Jaszai J, Galter D, Krohn K, Unsicker K (1998) Glial cell line-derived neurotrophic factor requires transforming growth factor-beta for exerting its full neurotrophic potential on peripheral and CNS neurons. J Neurosci 18:9822-9834.

Krieglstein K, Richter S, Farkas L, Schuster N, Dünker N, Oppenheim RW, Unsicker K (2000) Reduction of endogenous transforming growth factors beta prevents ontogenetic neuron death. Nat Neurosci 3:1085-1090.

Leitner ML, Molliver DC, Osborne PA, Vejsada R, Golden JP, Lampe PA, Kato AC, Milbrandt J, Johnson EM Jr (1999) Analysis of the retrograde transport of glial cell line-derived neurotrophic factor (GDNF), neurturin, and persephin suggests that in vivo signaling for the GDNF family is GFR $\alpha$ coreceptor-specific. J Neurosci 19:9322-9331.

Li M, Sendtner M, Smith A (1995) Essential function of LIF receptor in motor neurons. Nature 378:724-727.

Liu T, Bauskin AR, Zaunders J, Brown DA, Pankhurst S, Russell PJ, Breit SN (2003) Macrophage inhibitory cytokine 1 reduces cell adhesion and induces apoptosis in prostate cancer cells. Cancer Res 63:5034-5040.

Manthorpe M, Skaper SD, Williams LR, Varon S (1986) Purification of adult rat sciatic nerve ciliary neuronotrophic factor. Brain Res 367: 282-286.

Masu Y, Wolf E, Holtmann B, Sendtner M, Brem G, Thoenen H (1993) Disruption of the CNTF gene results in motor neuron degeneration. Nature 365:27-32.

Matheson CR, Carnahan J, Urich JL, Bocangel D, Zhang TJ, Yan Q (1997) Glial cell line-derived neurotrophic factor (GDNF) is a neurotrophic factor for sensory neurons: comparison with the effects of the neurotrophins. J Neurobiol 32:22-32.

Oberle S, Schober A, Meyer V, Holtmann B, Henderson C, Sendtner M, Unsicker K (2006) Loss of leukemia inhibitory factor receptor beta or cardiotrophin-1 causes similar deficits in preganglionic sympathetic neurons and adrenal medulla. J Neurosci 26:1823-1832.

Oppenheim RW, Haverkamp LJ, Prevette D, McManaman JL, Appel SH (1988) Reduction of naturally occurring motoneuron death in vivo by a target-derived neurotrophic factor. Science 240:919-922.

Oppenheim RW, Wiese S, Prevette D, Armanini M, Wang S, Houenou LJ, Holtmann B, Gotz R, Pennica D, Sendtner M (2001) Cardiotrophin-1, a muscle-derived cytokine, is required for the survival of subpopulations of developing motoneurons. J Neurosci 21:1283-1291.

Rind HB, Butowt R, von Bartheld CS (2005) Synaptic targeting of retrogradely transported trophic factors in motoneurons: comparison of glial cell line-derived neurotrophic factor, brain-derived neurotrophic factor, and cardiotrophin-1 with tetanus toxin. J Neurosci 25:539-549.

Schober A, Hertel R, Arumäe U, Farkas L, Jaszai J, Krieglstein K, Saarma M, Unsicker K (1999) Glial cell line-derived neurotrophic factor rescues target-deprived sympathetic spinal cord neurons but requires transforming growth factor-beta as cofactor in vivo. J Neurosci 19:2008-2015.

Schober A, Böttner M, Strelau J, Kinscherf R, Bonaterra GA, Barth M, Schilling L, Fairlie WD, Breit SN, Unsicker K (2001) Expression of growth differentiation factor-15/macrophage inhibitory cytokine-1 (GDF-15/MIC-1) in the perinatal, adult, and injured rat brain. J Comp Neurol 439:32-45.

Sendtner M, Stöckli KA, Thoenen H (1992) Synthesis and localization of ciliary neurotrophic factor in the sciatic nerve of the adult rat after lesion and during regeneration. J Cell Biol 118:139-148.

Sendtner M, Carroll P, Holtmann B, Hughes RA, Thoenen H (1994) Ciliary neurotrophic factor. J Neurobiol 25:1436-1453.

Sendtner M, Götz R, Holtmann B, Escary JL, Masu Y, Carroll P, Wolf E, Brem G, Brület P, Thoenen H (1996) Cryptic physiological trophic support of motoneurons by LIF revealed by double gene targeting of CNTF and LIF. Curr Biol 6:686-694.

Sendtner M, Pei G, Beck M, Schweizer U, Wiese S (2000) Developmental motoneuron cell death and neurotrophic factors. Cell Tissue Res 301:71-84.

Stöckli KA, Lottspeich F, Sendtner M, Masiakowski P, Carroll P, Götz R, Lindholm D, Thoenen H (1989) Molecular cloning, expression and regional distribution of rat ciliary neurotrophic factor. Nature 342: 920-923.

Strelau J, Sullivan A, Böttner M, Lingor P, Falkenstein E, Suter-Crazzolara C, Galter D, Jaszai J, Krieglstein K, Unsicker K (2000) Growth/differentiation factor-15/macrophage inhibitory cytokine-1 is a novel trophic factor for midbrain dopaminergic neurons in vivo. J Neurosci 20:8597-8603.

von Bartheld CS (2001) Tracing with radiolabeled neurotrophins. Methods Mol Biol 169:195-216.

Wiese S, Pei G, Karch C, Troppmair J, Holtmann B, Rapp UR, Sendtner M (2001) Specific function of B-Raf in mediating survival of embryonic motoneurons and sensory neurons. Nat Neurosci 4:137-142.

Yang H, Filipovic Z, Brown D, Breit SN, Vassilev LT (2003) Macrophage inhibitory cytokine-1: a novel biomarker for $\mathrm{p} 53$ pathway activation. Mol Cancer Ther 2:1023-1029. 